\title{
Cost-Effectiveness of Gas Industry Development Strategy
}

\author{
Alexander S. Kazak ${ }^{1, *}$ and Vladimir N. Bashkin ${ }^{2,3}$ \\ ${ }^{I}$ NIIGazeconomica LLC, Staraya Basmannaya st., 20-8, Moscow, 105066 Russia \\ ${ }^{2}$ Gazprom VNIIGAZ LLC, Razvilka, Leninsky District, Moscow Region, 142719 Russia \\ ${ }^{3}$ Institute of Physicochemical and Biological Problems of Soil Science RAS, Pushchino, Moscow Region 142292 Russia
}

\begin{abstract}
This paper was aimed to show the approaches to geo-economic estimation, investment risk as well as methods of estimating investment risk for sustainable development of gas industry.
\end{abstract}

Keywords: Geo-economic estimation, investment risk, sustainable development, strategy

\section{INTRODUCTION}

Currently, under geo-economic and eco-economic estimation of hydrocarbon (gas, oil and gas condensate, generally, HC) resources and reserves, we assume the triune process combining, firstly, the estimation of $\mathrm{HC}$ recoverable resources or reserves, secondly, the substantiation of HC production indices, and, thirdly, the calculation of the effectiveness of estimated field development. The main purpose of this process is to give objective ideas about the resources and economic potential of revealed or predictable fields, and also about the degree of risk of participation in investment projects on developing $\mathrm{HC}$ resources and reserves. These ideas must provide the selection of the most effective objects and directions for exploration and development of gas and oil fields. The assigned tasks take on a special role and value for the polar project, both terrestrial and marine ones, field development of which is related with the need of very high expenditures and respectively requires the most economically and environmentally sound planning of works (Samsonov et al. 2007).

As regards the gas transportation systems in the Polar areas, the key economic indicators of any gas transportation system are investments and rated gas transportation tariff. These indicators are interdependent. Investments play the dominant role in the reduced project cost and, hence, tariff calculations.

Investments in the linear part of gas pipeline significantly depend on the diameter, pressure, number of strings and insignificantly depend on the grade of steel or well thickness. Investments to compressor stations (these are in the Polar regions as the head ones mainly) significantly depend on the

*Address correspondence to this author at Institute of Economics \& Management of Gas Industry LLC, Gazprom (NIIgazeconomica), Staraya Basmannaya st., 20-8, Moscow, 105066 Russia; Tel: +7 499 265-24-20;

Fax: +7 499 267-30-76; E-mail: a.kazak@econom.gazprom.ru capacity and increment of compressor stations, and insignificantly depend on the working pressure, diameter and degree of compression. Investments to infrastructure are taken to be conditionally fixed.

From the point of view of sustainability of gas industry development, the consideration of different parameters determining the cost-effectiveness of the gas industry development strategy both for production and transportation stages in the Polar Regions of Russia is of great importance.

\section{COST-EFFECTIVENESS OF THE GAS INDUSTRY DEVELOPMENT STRATEGY}

Cost-effectiveness of the gas industry development strategy in a particular country is typically evaluated according to the World Bank recommendations and the UNIDO (United Nations Industrial Development Organization) Guidelines for the Preparation of Industrial Feasibility Studies (Manual 1995; Rusakova 2010). As stated in these documents, the key cost-effectiveness indices of any development strategy are the world's most widely used economic criteria based on the cash flow, which include:

a) net value (NV);

b) net present value (NPV);

c) internal rate of return (IRR);

d) payback period (PB) for NV and NPV.

Calculations are made following the organizational and commercial scheme with an emphasis on the development indicators of particular business processes, including:

1) natural gas production;

2) gas condensate production;

3) trunk pipeline transmission of natural gas;

4) trunk pipeline transmission of gas condensate;

5) underground natural gas storage; 
6) natural gas processing;

7) gas condensate processing;

8) natural gas transmission along gas distribution pipelines;

9) sales of natural gas and liquid hydrocarbons.

Efficiency is evaluated in line with the following fundamental principles:

1) review of the project throughout the calculation period;

2) modeling of cash flows that cover all the revenues and expenses incurred during the project execution within the period under review;

3) comparability of conditions to weigh up various scenarios of the strategy implementation;

4) principle of the positive and maximum effect from an investor's perspective: a project may be recognized as an efficient one if its implementation has a positive effect and gives an investor adequate return on the capital invested;

5) timeline factor since it is necessary to take into account fluctuations and inequality of costs and benefits occurring in different time periods via discounted cash flow.

Performance indicators of gas industry development strategy are assessed on the basis of consolidated cash flow, which is a sum of cash flows of all the above-indicated business processes. In this case, investment, operational and financial cash flows are estimated separately.

\section{ASSESSING PROGRAM FITNESS FOR GAS INDUS- TRY SUSTAINABLE DEVELOPMENT}

The baseline data for evaluating the program's efficiency are:

a) production and sales volumes of marketable goods (gas, condensate and derivatives), capital investments and operational costs;

b) tax regime in compliance with the country's tax legislation.

Assessment of performance indicators for strategy implementation is made on the basis of reference prices (in real terms, fixed prices within the assessment period).

Decision-making on investment projects is complicated by such factors as the type of investment, cost of investment projects, multiple projects availability (or variants of one project), limited investment resources, risks associated with decision-making.

Decision-making on investments is based on formalized models and unconventional methods.

Although the World Bank recommendations and the UNIDO Guidelines are widely applied their implementation might be complicated by the following factors:

a) use of multiple data (economic and financial regulations) which could hardly be accessible without a sufficiently developed market economy;

b) large number of assumptions and simplifications; c) many important issues and evaluations remain at the analysts' discretion.

The main objective of evaluating an investment project's efficiency is to provide the decision-maker with information on the expected effects and risks, so that they could decide whether to launch a project, reject it, or adjust the proposed investment plan. As a result, interpretation of the evaluations becomes more important than the accuracy of particular indices.

Key criteria for choosing the best option are net discounted revenues, profitability index and internal rate of return, while for assessing data uncertainty, it is recommended to apply sensitivity and breakeven analysis. The key assumption should be a non-systemic approach to projecting. The aligned facilities are evaluated separately without reference to their interaction in the manufacturing and financial fields. A classical approach is strictly program-based and does not consider the possibility of adjusting the adopted decisions to a dynamic environment depending on various conditions.

Investment evaluations are based on regulations, price lists, accounting reports and other economic statistics as well as tax legislation. Massive array of data is subjected to rapid and unpredictable change over time and a good example may be cost estimates.

The proposed comprehensive investment projecting technique consists of the following stages:

1) defining the investment project's objectives and description of conditions for project implementation;

2) putting forth alternative project solutions for individual facilities;

3) providing cost estimations via methods and prototype analysis logic schemes in case of information insufficiency;

4) downloading baseline information into databases in line with the project options;

5) selecting rational options using multi-stage stochastic programming with probabilistic risk assessment;

6) comparing results according to typical schemes of the expert logic analysis;

7) carrying out methodical assessment of efficiency and data submission to the Client.

In the long-term planning and projecting presupposes some data uncertainty on the future costs and benefits. It is needed to expand a range of changes in such project-specific parameters of the environment as price, volume of product sales and other project implementation conditions.

It is also worthy to use data obtained during pre-project and project investigation of particular facilities in the form of process system options adjusted to the local criteria and characterized by various output capacity values. An aggregated calculation flow scheme is used to specify a combination of project options for various facilities, optimum construction timeframes and other aspects. 
Table 1. Calculation of approximate rate during the estimation of gas and oil resources and reserves with risk allowance

\begin{tabular}{|c|c|c|}
\hline Category of Resources and Reserves & Risk Premium, \% & Discount Rate with Risk Allowance, \% \\
\hline \hline $\mathrm{A}+\mathrm{B}+\mathrm{C}_{1}$ & 5 & 20 \\
\hline $\mathrm{C}_{2}$ & 10 & 20 \\
\hline $\mathrm{C}_{3}$ & 15 & 25 \\
\hline $\mathrm{D}_{1}$ & 20 & 30 \\
\hline $\mathrm{D}_{2}$ & 25 & 35 \\
\hline $\mathrm{D}_{3}$ & 30 & \\
\hline
\end{tabular}

Assessment of capital and operational costs of the facilities (basic initial optimization data on economic and financial criteria), requires to account for possible deviations of these indices from the estimated values and analysis of their resistance to initial data variations (economic regulations, price lists, data on prototypes) that are widely used in cost estimations. These studies may rely on the expert logic analysis schemes enabling to generate probability data assessments.

It is essential that long-term projects optimization should be based on probabilistic models that cover uncertainty of future system development conditions and operations. Such probabilistic forecasting models are to be structured by an expert and pertinent software.

Another crucial principle of investment projecting is the development of adaptive strategies for the dynamic development of the system where decision-making depends on the external conditions, company's business assets and financial status (Kudryavtsev et al. 2008; Kazak et al. 2009).

\section{METHODS OF ESTIMATING INVESTMENT RISK}

The concept of investment risk has currently become somewhat "fancy" and is "exploited" by many researches (Samsonov et al. 2007). Meanwhile, this "enthusiasm" is not, as a rule, beyond the scope of general discussion on this topic and is not accompanied with some significant quantitative characteristics. By its economic content investment risk is a synthesis of three above-mentioned components, i.e. geological, technological and economic risks.

The simplest parameter of risk estimation is IRR index. The higher this index, the higher "margin of safety" of a project, i.e. if future return from the project was taken in calculations too optimistic (or costs were underestimated) but in reality profits are lower (or the cost is higher), then the project with a sufficiently large IRR value has a good chance to be break-even.

The other distributed method of risk accounting under the deterministic approach is an application of risk correction in discount rate. This method is widely spread in the United States of America. The U.S. specialized consulting companies even use sometimes a certain standardized classifier, with the help of which the discount rate is calculated for this or that project. The state securities yield that does not exceed $4-5 \%$ a year is taken as a risk-free rate.
When we invest the existing industry without changing a range of goods, a minimum risk extra charge is taken in amount of $3-5 \%$. In this case a discount rate for such projects will be in the interval $7-10 \%$.

At substitute investments, when the industry is modernized more radically (machinery or equipment of new generation are introduced) or the range of goods is changed (new models or goods which are not widely used in the market), the risk premium is taken in the interval of 5-10\% a year, and the discount rate becomes equal to $8-15 \%$ a year, etc. These are many intermediate positions in this classification. The list is completed with the investments put into fundamental research activities the tasks of which are not clearly defined and the result is unknown in advance. In this case the risk premium will be the highest and will amount to $20-25 \%$, and the discount rate will be accordingly $25-30 \%$.

A net discount income is calculated based on the discount rates obtained. If the income is positive, the project is accepted with risk allowance.

In principle, such analogy can be drawn with economic estimation of resources and reserves under the deterministic approach bearing in mind the projects in the Polar regions. The lowest risk is associated with the reserves of commercial categories $(A+D+C)$ and the highest risk with the resources of categories $\mathrm{D}_{2}$. In Table $\mathbf{1}$, given below we suggest, as a discussion, risk premiums during the economic estimation resources and reserves in accordance with their classification accepted in Russia. For example, a saving bank rate on fixed foreign currency deposits in amount of 5-7\% a year (let us take $5 \%$ ) can be assumed as a risk-free rate. Then summing this risk-free rate with risk premiums we will obtain the corresponding discount rate.

Certainly, these risk premiums can be different in various specific conditions, such as, for example for the Polar region, the terrestrial and offshore exploration gas fields, and as well any expert evaluation can be subjective. This is a main disadvantage of all deterministic methods. Such approach to economic estimation may consider approximately a large uncertainty in estimate of low category resources and ensuing risk.

Besides, the risk can be also related with the uncertainties of forecasting technological indices of the field development.

Technological risk depends, to a great extent, on geological risk, as the uncertainty in geological model of a field re- 
Table 2. Geological, technological and cost parameters of a forecasted field.

\begin{tabular}{|c|c|c|c|c|}
\hline \multirow[t]{2}{*}{ Group of Parameters } & \multirow[t]{2}{*}{ Name of Parameter } & \multicolumn{2}{|c|}{ Change Limit } & \multirow[t]{2}{*}{ Type of Distribution } \\
\hline & & From & To & \\
\hline \multirow[t]{3}{*}{ Q } & $\mathrm{G} / \mathrm{N}$ ratio & 0.6 & 0.8 & Norm. \\
\hline & Oil density & 0.89 & 0.93 & Norm \\
\hline & Recovery factor & 0.3 & 0.35 & Norm. \\
\hline Technological & Year of reaching max. production & 4 & 6 & Norm. \\
\hline$\Omega$ & Year of declining production beginning & 7 & 9 & Norm. \\
\hline Cost & Oil price, $\mathrm{t}$ & 120 & 150 & Norm. \\
\hline \multirow[t]{3}{*}{$\Psi$} & Cost of productive well, US $\$ / \mathrm{m}$ & 160 & 828 & Norm. \\
\hline & Cost of 1-km pipeline, mln US\$ & 0.12 & 0.15 & Norm. \\
\hline & Cost of 1 platform, mln US\$ & 16.0 & 27.0 & Norm. \\
\hline
\end{tabular}

sults in the uncertainty of its development plan, system and volume of its construction, design outputs of gas and oil, etc. Besides, the forecast of HC supply security and the volume of their production depend also on correct accounting of some specific types of technological risk, i.e. the frequency of calculated damages and failures on well, equipment and pipelines.

Economic risk, in turn, depends both on geological and technological risks (uncertainty in the estimation of expenses on exploration, development and infrastructure) and relative suddenness of long-range end product sale prices and tax treatment (will be their PCA regime and how will rates of different taxes change during subsequent 20-25 years, etc.?). The result of economic estimation depends, to a great extent, on these parameters.

During the estimation of resources these factors are more uncertain from the point of view of the present situation. Nevertheless, Table 2 indicates some relative values for estimation of the needed parameters as random cost indices (Samsonov et al. 2007).

In the economic literature risk is usually estimated as a measure of uncertainty in a final results estimate. In Markovits's classical problem risk is measured through the dispersion of estimates of investment portfolio, which should be minimized. In our case the investment risk may be measured by the dispersion of estimates of investment project efficiency.

\section{CONCLUSION}

Bearing in mind the abovementioned materials, we should conclude that development of new facilities may induce two types of risks:

1) risks associated with the absence of demand for these capacities (not used efficiently) if the situation is changed versus the one originally planned;

2) risks associated with the scarcity of the company's financial resources which may impede the system's adaptation to the changes. Decisions on new facilities construction may be valid only if it is coupled with assessment of the system's adaptive capabilities. This may be achieved only by means of multi-stage stochastic programming followed by the quantitative assessment of risks' impact on decision efficiency indicators.

\section{CONFLICT OF INTEREST}

The authors confirm that this article content has no conflict of interest.

\section{ACKNOWLEDGEMENTS}

The authors express their deep appreciation and gratitude to Prof. Dr. P. Nikitin, Gazprom VNIIGAG, for the consultation and active participation during result discussions. 


\section{REFERENCES}

Kazak, AS, Mescherin, IV, Kudryavtsev, IB \& Gitman, IS (2009) Optimal locations for LNG plants and LNG consumers units. Management Systems and Information Technologies, 1 (35), 80-1.

Kudryavtsev, IB, Kislenko, NA, Kazak, AS \& Kudryavtsev, AA (2008) Mathematical models for commercial flows rational distribution in trunk pipelines. Oil, Gas and Business, 4, 74-6.

Manual for the Preparation of Industrial Feasibility Studies (1995), UNIDO. Available from: http://www.unido.org/en/resources/publications/publications-by-type/sales-publications/manual-for-the-preparation of-industrial-feasibility-studies.html
Risk Management Standards (2003) Risk Management. Russian Risk Management Society, Moscow.

Rusakova, VV (2010) Cost-effectiveness analysis in gas industry development strategy. Science and Technology in Gas Industry, 2 (42), 824.

Samsonov, RO, Kazak, AS \& Bashkin, VN (2007) Master Plan Methodology For gas Industry Development, Gazprom VNIIGAZ, Moscow.

Markelov, VA, Andreev, OP \& Kobylkin DN (Eds.) (2013) Sustainable Development of Gas Industry, Nedra Publishers, Moscow.

Received: November 12, 2014

Revised: December 01, 2014

Accepted: December 28, 2014

(c) Kazak and Bashkin; Licensee Bentham Open.

This is an open access article licensed under the terms of the Creative Commons Attribution Non-Commercial License (http://creativecommons.org/ licenses/by-nc/3.0/), which permits unrestricted, non-commercial use, distribution and reproduction in any medium, provided the work is properly cited. 